See discussions, stats, and author profiles for this publication at: https://www.researchgate.net/publication/336561155

\title{
Analisis Pengaruh Temperatur dan Laju Aliran Massa Cooling Water Terhadap Efektivitas Kondensor di PT. Geo Dipa Energi Unit Dieng
}

\section{Article $\cdot$ August 2019}

DOI: $10.14710 /$ rotasi.21.3.155-159

\section{CITATIONS}

5 authors, including:

Eflita Yohana

Universitas Diponegoro

24 PUBLICATIONS 17 CITATIONS

SEE PROFILE

Nazaruddin Sinaga

Universitas Diponegoro

101 PUBLICATIONS 153 CITATIONS

SEE PROFILE

Some of the authors of this publication are also working on these related projects:

Project Syngas power generator View project

Project Dynamometer View project
READS

111

Bangkit Farizki

Universitas Diponegoro

1 PUBLICATION 0 CITATIONS

SEE PROFILE

Mohamad Endy Yulianto

Universitas Diponegoro

47 PUBLICATIONS 33 CITATIONS

SEE PROFILE 


\title{
Analisis Pengaruh Temperatur dan Laju Aliran Massa Cooling Water Terhadap Efektivitas Kondensor di PT. Geo Dipa Energi Unit Dieng
}

\author{
*Eflita Yohana ${ }^{a}$, Bangkit Farizkia ${ }^{a}$ Nazaruddin Sinaga ${ }^{a}$, Mohamad Endy Julianto ${ }^{\text {b }}$ Indah Hartatic

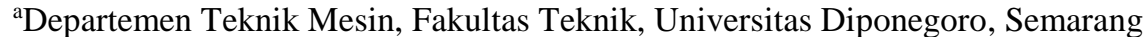 \\ ${ }^{b}$ Departemen Teknik Kimia, Sekolah Vokasi, Universitas Diponegoro, Semarang \\ 'Program Studi Teknik Kimia, Universitas Wahid Hasyim, Semarang \\ *E-mail: efnan2003@gmail.com
}

\begin{abstract}
The condenser is a heat exchanger apparatus that serves to condense the steam output of the turbine. The performance of a condenser can be seen from the value of its effectiveness. The effectiveness of the condenser is influenced by several factors such as steam flow and cooling water flow. An important factor that affects the performance of condensers is the amount of cooling water circulation that goes into the condenser. Condenser used in PT. Geo Dipa Energi Dieng Unit is a type of direct-contact condenser where cooling water is sprayed into the condenser through nozzles so that the granules are shaped. Furthermore, the granules will be in direct contact with the vapor granules of turbine output resulting in condensation marked by the growth of grain size cooling water. By knowing the influence of temperature and mass flow rate of cooling water to the effectiveness of condenser hence can known performance of condenser that exist in PT. Geo Dipa Energi Dieng Unit. From the calculation using the effective method of NTU obtained the highest effectiveness of $92.02 \%$ is generated when the cooling water temperature entering the condenser is $19.89^{\circ} \mathrm{C}$ and the mass flow rate of cooling water entering the condenser is 2,392.12 kg/s. So it can be concluded that the existing condenser PT. Geo Dipa Energi Unit Dieng still have a good performance.
\end{abstract}

Keywords: cooling water; direct contact condenser; effectiveness-NTU

\section{Abstrak}

Kondensor merupakan alat penukar kalor yang berfungsi untuk mengkondensasikan uap keluaran turbin. Kinerja dari suatu kondensor dapat dilihat dari nilai efektivitasnya. Efektivitas kondensor dipengaruhi oleh beberapa faktor antara lain aliran steam dan aliran cooling water. Faktor penting yang berpengaruh terhadap kinerja kondensor adalah banyaknya sirkulasi cooling water yang masuk ke kondensor. Kondensor yang digunakan di PT. Geo Dipa Energi Unit Dieng adalah jenis direct-contact condenser dimana cooling water disemprotkan ke dalam kondensor melalui nosel-nosel sehingga berbentuk butiran-butiran. Selanjutnya butiran-butiran tersebut akan bersentuhan langsung dengan butiran-butiran uap keluaran turbin sehingga terjadi kondensasi yang ditandai dengan pertumbuhan ukuran butiran cooling water. Dengan mengetahui pengaruh temperatur dan laju aliran massa cooling water terhadap efektivitas kondensor maka dapat diketahui performa kondensor yang ada di PT. Geo Dipa Energi Unit Dieng. Dari hasil perhitungan menggunakan metode efektivitas NTU diperoleh efektivitas tertinggi sebesar $92,02 \%$ dihasilkan pada saat temperatur cooling water yang masuk kondensor sebesar $19,89{ }^{\circ} \mathrm{C}$ dan laju aliran massa cooling water yang masuk kondensor sebesar $2.392,12 \mathrm{~kg} / \mathrm{s}$. Sehingga dapat disimpulkan bahwa kondensor yang ada PT. Geo Dipa Energi Unit Dieng masih mempunyai performa yang baik.

Kata kunci : cooling water; kondensor kontak langsung; efektivitas NTU.

\section{Pendahuluan}

Kinerja siklus pembangkit listrik tenaga uap dipengaruhi oleh berbagai faktor, salah satunya adalah kinerja dari suatu kondensor. Kondensor merupakan alat penukar kalor yang menerima panas dari turbin uap yang akan diubah menjadi air kondensat setelah melalui proses perpindahan panas [1]. Fungsi utama kondensor adalah mengkondensasikan uap keluaran turbin [2]. Kinerja dari suatu kondensor dapat dilihat dari nilai efektivitasnya. Efektivitas kondensor merupakan perbandingan antara laju perpindahan panas aktual yang terjadi dengan laju perpindahan panas maksimum yang mungkin terjadi secara termodinamika di dalam kondensor [3]. Perhitungan efektifitas kondensor dipengaruhi oleh beberapa faktor antara lain aliran steam dan aliran cooling water [4]. Faktor yang berpengaruh dalam aliran cooling water adalah besarnya temperatur dan laju aliran massa cooling water yang masuk ke 
kondensor. Nilai temperatur dan laju aliran massa cooling water yang masuk ke kondensor mempunyai variasi nilai yang beragam. Oleh karena itu diperlukan penelitian mengenai pengaruh temperatur dan laju aliran massa cooling water terhadap efektivitas kondensor.

Salah satu penelitian mengenai efektivitas kondensor kontak langsung pernah dilakukan oleh Amrina Rosyada, dkk dari Politeknik Negeri Jakarta, Indonesia [5]. Penelitian tersebut melakukan perbandingan antara nilai efektivitas kondensor sebelum dan sesudah overhoul di PT. PGE Unit IV. Dari penelitian tersebut diperoleh nilai efektivitas ratarata sebelum overhoul sebesar 54,08\%. Sedangkan nilai efektivitas rata-rata sesudah overhoul sebesar 54,11\%.

Selain menentukan nilai efektivitas kondensor kontak langsung, terdapat penelitian yang dilakukan oleh Syed Haider Ali, dkk dari Universiti Teknologi PETRONAS, Malaysia [6]. Penelitian yang dilakukan yaitu mengenai pengaruh rendahnya tekanan kondensor terhadap performa siklus secara keseluruhan. Besarnya nilai tekanan kondensor tersebut dipengaruhi oleh laju aliran massa dan temperatur cooling water yang masuk ke kondensor. Dari penelitian tersebut diperoleh hasil bahwa nilai perpindahan panas menurun karena temperatur cooling water yang masuk kondensor meningkat dan semakin kecil laju aliran masa cooling water yang masuk kondensor mengakibatkan perpindahan panas yang terjadi juga semakin kecil.

Penelitian mengenai analisis pengaruh temperatur dan laju aliran massa terhadap efektivitas kondensor di PT. Geo Dipa Energi Unit Dieng merupakan penelitian yang baru dilakukan. Penelitian ini bertujuan untuk mengetahui pengaruh temperatur dan laju aliran massa cooling water terhadap efektivitas kondensor sehingga dapat diketahui performa kondensor yang ada di PT. Geo Dipa Energi Unit Dieng.

\section{Dasar Teori}

Menurut Kays dan London, efektivitas adalah perbandingan antara laju aliran panas yang aktual dengan laju aliran panas maksimal yang dapat ditransfer [8]. Rumus efektivitas menggunakan metode NTU dapat ditentukan menggunakan rumus [9].

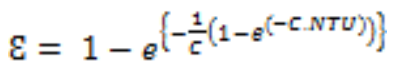

dimana:

$$
\begin{array}{ll}
\varepsilon & =\text { Efektivitas kondensor }(\%) \\
\text { C } & =\text { Rasio kapasitas } \\
\text { NTU } & =\text { Number of Transfer Unit }
\end{array}
$$

Persaamaan efektivitas melibatkan suatu besaran yang tak berdimensi. Besaran ini disebut dengan Number of Transfer Unit (NTU). Nilai NTU merupakan ukuran dari luas permukaan alat penukar kalor, sehingga semakin besar NTU semakin besar pula ukuran alat penukar kalor. Besarnya nilai NTU dapat ditentukan menggunakan rumus [4].

$$
\begin{aligned}
& N T U=\frac{U_{-A}}{C_{\min }}=\frac{U_{-A}}{C_{s}} \\
& U \cdot A=\frac{Q}{U \operatorname{LND} D}
\end{aligned}
$$

dimana:

$$
\begin{array}{ll}
\mathrm{U} & =\text { Koefisien perpindahan kalor menyeluruh }\left(\mathrm{W} / \mathrm{m}^{20} \mathrm{C}\right) \\
\mathrm{A} & =\text { Luas perpindahan kalor }\left(\mathrm{m}^{2}\right) \\
\mathrm{C}_{\mathrm{s}} & =\text { Kapasitas panas steam }\left(\mathrm{kJ} / \mathrm{s}^{\circ} \mathrm{C}\right)
\end{array}
$$

Selain NTU yang merupakan besaran yang tak berdimensi, terdapat pula nilai C yang besarannya tak berdimensi. Rasio kapasitas (C) dapat ditentukan dengan membandingkan kapasitas panas minimum dengan kapasitas panas maksimum. Nilai kapasitas rasio dapat ditentukan menggunakan rumus [4].

$$
\begin{aligned}
& C=\frac{c_{\min }}{c_{\max }}=\frac{C_{s}}{C_{\mathrm{gW}}} \\
& C_{g}=m_{g} x C_{p_{s}} \\
& C_{C W}=m_{c w} x C_{P_{C W}}
\end{aligned}
$$

dimana:

$$
\begin{array}{ll}
\mathrm{C}_{\mathrm{s}} & =\text { Kapasitas panas steam }\left(\mathrm{kJ} / \mathrm{s}^{\circ} \mathrm{C}\right) \\
\mathrm{C}_{\mathrm{cw}} & =\text { Kapasitas panas cooling } \text { water }\left(\mathrm{kJ} / \mathrm{s}^{\circ} \mathrm{C}\right) \\
\mathrm{m}_{\mathrm{s}} & =\text { Laju aliran masa steam masuk kondensor }(\mathrm{kg} / \mathrm{s}) \\
\mathrm{m}_{\mathrm{cw}} & =\text { Laju aliran masa cooling water masuk kondensor }(\mathrm{kg} / \mathrm{s}) \\
\mathrm{Cp}_{\mathrm{s}} & =\text { Panas spesifik steam }\left(\mathrm{kJ} / \mathrm{kg}^{\circ} \mathrm{C}\right) \\
\mathrm{Cp}_{\mathrm{cw}} & =\text { Panas spesifik cooling water }\left(\mathrm{kJ} / \mathrm{kg}^{\circ} \mathrm{C}\right)
\end{array}
$$


Besarnya koefisien pindah panas menyeluruh dapat diperoleh dari perhitungan laju perpindahan kalor (Q) dan perhitungan LMTD (Log Mean Temperature Difference). Nilai laju perpindahan panas dapat ditentukan menggunakan rumus [4].

$$
\begin{aligned}
& Q=m_{g} x C_{p_{g}} x \Delta T \\
& Q=m_{g} x C_{p_{s}} x\left(T_{g} i n-T_{C W} i n\right)
\end{aligned}
$$

Dengan kondensor yang mempunyai arah aliran yang berlawanan (counter flow) maka LMTD dapat dihitung menggunakan rumus [4].

$$
\begin{aligned}
& L M T D=\frac{\Delta T_{1}-\Delta T_{2}}{\operatorname{In}\left(\frac{\Delta T_{1}}{\Delta T_{2}}\right)} \\
& \Delta T_{1}=T_{g} \text { in }-T_{C W V} \text { out } \\
& \Delta T_{2}=T_{g} \text { out }-T_{C W} \text { in }
\end{aligned}
$$

dimana:

$\mathrm{T}_{\mathrm{s}}$ in $\quad=$ Temperature steam masuk kondensor $\left({ }^{\circ} \mathrm{C}\right)$

$\mathrm{T}_{\mathrm{s}}$ out $\quad=$ Temperature steam keluar kondensor $\left({ }^{\circ} \mathrm{C}\right)$

$\mathrm{T}_{\mathrm{cw}}$ in $\quad=$ Temperature cooling water masuk kondensor $\left({ }^{\circ} \mathrm{C}\right)$

$\mathrm{T}_{\mathrm{cw}}$ out $\quad=$ Temperature cooling water keluar kondensor $\left({ }^{\circ} \mathrm{C}\right)$

\section{Metode Penelitian}

Kondensor yang digunakan dalam penelitian ini adalah jenis direct-contact condenser. Pada kondensor jenis ini, cooling water disemprotkan ke dalam kondensor melalui nosel-nosel sehingga berbentuk butiran-butiran. Selanjutnya butiran-butiran tersebut akan bersentuhan dengan butiran-butiran uap keluaran turbin sehingga terjadi kondensasi yang ditandai dengan pertumbuhan ukuran butiran cooling water [2]. Gambar 1(a) merupakan kondensor kontak langsung di PT. Geo Dipa Energi Unit Dieng sedangkan Gambar 1(b) merupakan skema kondensor kotak langsung.

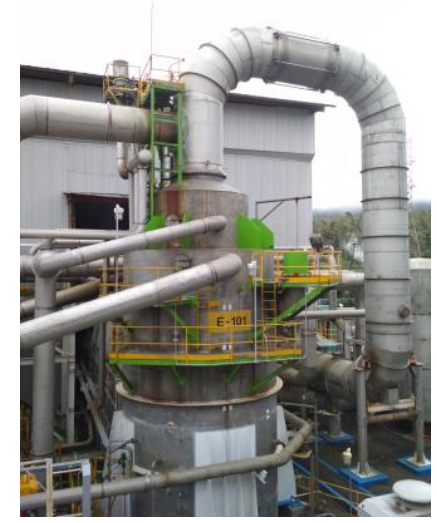

(a)

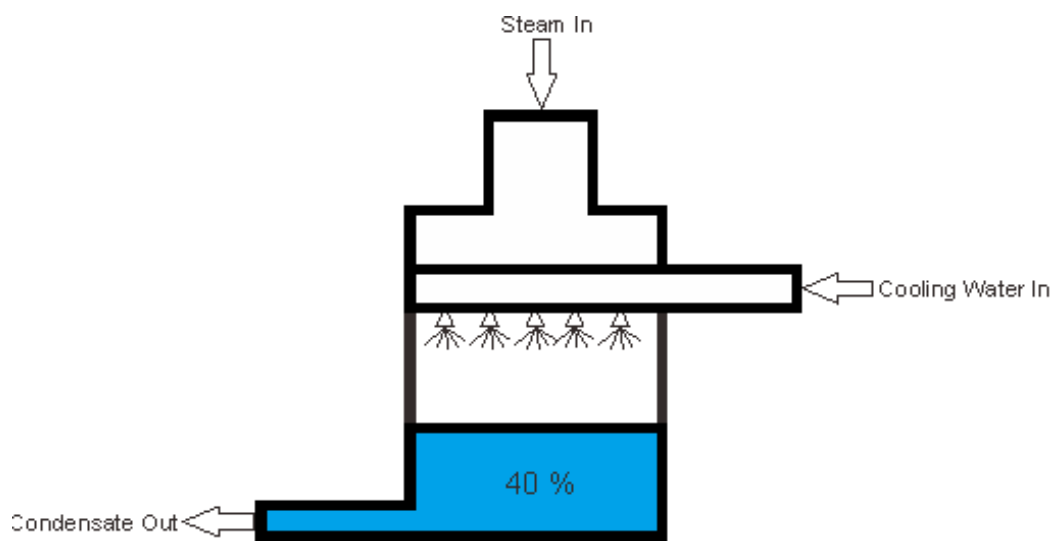

(b)

Gambar 1. (a) Kondensor kontak langsung [7], (b) Skema kondensor kontak langsung [7].

Penelitian dilakukan dengan mengumpulkan data-data yang dibutuhkan dalam perhitungan efektivitas kondensor. Data yang dibutuhkan berupa laju alir dari steam, temperatur masuk dan keluar steam, temperatur masuk dan keluar cooling water, serta kapasitas panas steam dan cooling water. Setelah data terkumpul dilanjutkan dengan perhitungan. Perhitungan dan pengolahan data dilakukan secara analitik berdasarkan persamaan 1 hingga persamaan 11. Setelah dilakukan perhitungan maka diperoleh besarnya efektivitas kondensor sehingga dapat diketahui performa kondensor yang ada di PT. Geo Dipa Energi Unit Dieng.

Data yang terkumpul selanjutnya akan diolah untuk menghitung nilai efektivitas kondensor. Data steam dan cooling tower yang digunakan diperoleh dari pengamatan pada tanggal 1-20 Januari 2018. Tabel 1 menunjukan data steam dan cooling water dari hasil pencatatan. 
Tabel 1. Data steam dan cooling water yang masuk kondensor [7].

\begin{tabular}{ccccccc}
\hline Data & Ts in $\left({ }^{\mathbf{}} \mathbf{C}\right)$ & $\begin{array}{c}\text { Ts out } \\
\left({ }^{\mathbf{C}} \mathbf{C}\right)\end{array}$ & ms $(\mathbf{k g} / \mathbf{s})$ & $\begin{array}{c}\text { Tcw in } \\
\left({ }^{\circ} \mathbf{C}\right)\end{array}$ & $\begin{array}{c}\text { Tcw out } \\
\left({ }^{\circ} \mathbf{C}\right)\end{array}$ & $\begin{array}{c}\text { mcw } \\
(\mathbf{k g} / \mathbf{s})\end{array}$ \\
\hline 1 & 42,52 & 39,44 & 96,35 & 21,32 & 39,44 & 2334,22 \\
\hline 2 & 43,22 & 39,24 & 97,42 & 21,10 & 39,24 & 2320,21 \\
\hline 3 & 41,28 & 39,72 & 96,55 & 20,88 & 39,72 & 2233,92 \\
\hline 4 & 43,34 & 40,12 & 97,89 & 20,90 & 40,12 & 2373,56 \\
\hline 5 & 42,44 & 40,34 & 96,32 & 22,63 & 40,34 & 2263,43 \\
\hline 6 & 42,66 & 39,92 & 96,68 & 21,78 & 39,92 & 2356,42 \\
\hline 7 & 42,38 & 39,60 & 97,34 & 21,24 & 39,60 & 2245,62 \\
\hline 8 & 43,34 & 38,98 & 97,33 & 20,18 & 38,98 & 2221,78 \\
\hline 9 & 41,78 & 39,12 & 97,82 & 20,10 & 39,12 & 2370,25 \\
\hline 10 & 42,92 & 40,16 & 96,76 & 20,86 & 40,16 & 2369,61 \\
\hline 11 & 43,21 & 39,69 & 96,31 & 21,72 & 39,69 & 2279,76 \\
\hline 12 & 43,42 & 40,92 & 97,22 & 21,80 & 40,92 & 2380,45 \\
\hline 13 & 42,52 & 41,52 & 96,63 & 22,34 & 41,52 & 2231,24 \\
\hline 14 & 42,88 & 40,56 & 97,21 & 22,56 & 40,56 & 2265,93 \\
\hline 15 & 43,21 & 39,91 & 97,89 & 22,74 & 39,91 & 2276,38 \\
\hline 16 & 41,77 & 39,93 & 97,33 & 21,94 & 39,93 & 2288,33 \\
\hline 17 & 42,44 & 39,69 & 96,21 & 20,86 & 39,69 & 2211,29 \\
\hline 18 & 43,44 & 39,38 & 96,12 & 20,97 & 39,38 & 2210,32 \\
\hline 19 & 41,96 & 39,52 & 97,25 & 19,89 & 39,52 & 2392,12 \\
\hline 20 & 42,31 & 39,22 & 96,88 & 20,13 & 39,22 & 2256,78 \\
\hline
\end{tabular}

\section{Hasil dan Pembahasan}

Syed Haider Ali, dkk dalam penelitiannya menyatakan bahwa nilai perpindahan panas menurun karena temperatur cooling water yang masuk kondensor meningkat akibat dari gradien temperatur antara dua aliran yang menurun dan semakin kecil laju aliran masa cooling water yang masuk kondensor mengakibatkan perpindahan panas yang terjadi juga semakin kecil karena laju aliran massa berbanding lurus dengan perpindahan panas [6]. Nilai laju perpindahan panas juga sebanding dengan nilai efektivitas kondensor [10]. Gambar 2 menunjukkan grafik mengenai pengaruh temperatur dan laju aliran massa cooling water terhadap laju perpindahan panas kondensor.

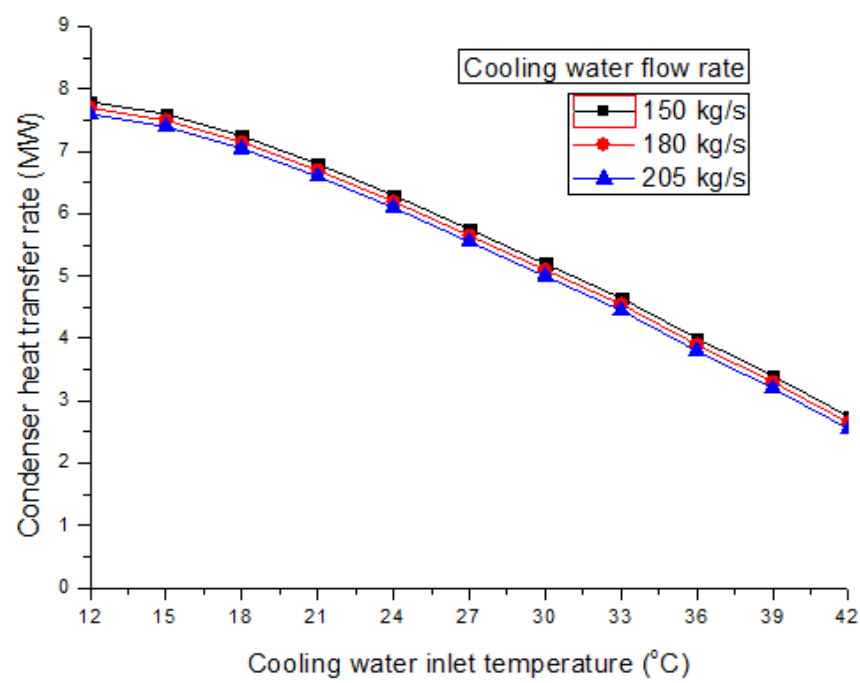

Gambar 2. Grafik pengaruh temperatur dan laju aliran massa cooling water terhadap laju perpindahan panas kondensor

Dari hasil penelitian diperoleh grafik pengaruh temperatur dan laju aliran massa cooling water terhadap efektivitas kondensor sebagai berikut. Gambar 3 menunjukkan grafik mengenai pengaruh temperatur dan laju aliran massa cooling water terhadap efektivitas kondensor. Gambar 3 menyatakan pengaruh temperatur dan laju aliran massa cooling water terhadap efektivitas kondensor. Dimana nilai temperatur cooling water yang semakin tinggi mengakibatkan efektivitas kondensor semakin rendah. Efektivitas kondensor tertinggi sebesar 92,02\% dihasilkan pada temperatur cooling water 
$19,89^{\circ} \mathrm{C}$ dan laju aliran massa cooling water yang masuk kondensor sebesar $2.380,45 \mathrm{~kg} / \mathrm{s}$. Sedangkan efektivitas kondensor terendah sebesar $91,34 \%$ dihasilkan pada temperatur cooling water $22,74^{\circ} \mathrm{C}$ dan laju aliran massa cooling water yang masuk kondensor sebesar $2.210,32 \mathrm{~kg} / \mathrm{s}$.

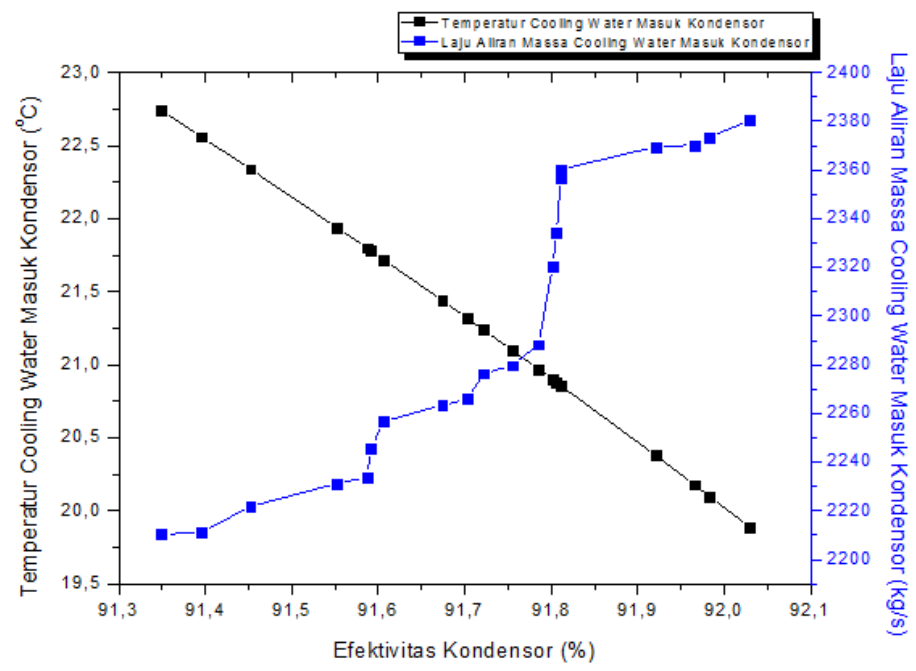

Gambar 3. Grafik pengaruh temperatur dan laju aliran massa cooling water terhadap efektivitas kondensor

\section{Kesimpulan}

Efektivitas kondensor tertinggi sebesar $92,02 \%$ dihasilkan pada temperatur cooling water sebesar $19,89^{\circ} \mathrm{C}$ dan laju aliran massa cooling water yang masuk kondensor sebesar $2.380,45 \mathrm{~kg} / \mathrm{s}$. Sedangkan efektivitas kondensor terendah sebesar 91,34 \% dihasilkan pada temperatur cooling water sebesar $22,74^{\circ} \mathrm{C}$ dan laju aliran massa cooling water yang masuk kondensor sebesar 2.210,32 kg/s. Karena nilai efektivitas kondensor masih sesuai dengan data commissioning maka dapat disimpulkan bahwa kondensor yang ada PT. Geo Dipa Energi Unit Dieng masih mempunyai performa yang baik.

\section{Daftar Pustaka}

[1] Sukarno, A., Bono, Budhi P., 2014, "Analisis Perubahan Tekanan Vakum Kondensor Terhadap Kinerja Kondensor di PLTU Tanjung Jati B Unit 1", Jurnal Teknik Energi, Vol (10), No. 2, Hal. 65-71.

[2] Apriyanti, V., Ari D.P., Abdurrachim, Willy A., Ridwan A., 2015, "Perancangan Perangkat Eksperimen Kondensasi Kontak Langsung dengan Keberadaan Non Condensable Gas", Proceeding Seminar Nasional Tahunan Teknik Mesin XIV (SNTTM XIV), Banjarmasin.

[3] Chandrasa, S., 2015, "Analisis Pengaruh Efektivitas Perpindahan Panas dan Tahanan Termal Terhadap Rancangan Termal Alat Penukar Kalor Shell \& Tube", Jurnal SINERGI, Vol (19), No. 1, Hal. 19-24.

[4] Lini, A. S. Z., Bayu R., 2016, "Penentuan Nilai Efektivitas Condenser di PLTU Paiton Unit 5 PT. YLT Jawa Timur", Jurnal Ilmiah Rotary, Vol (1), No. 1, Hal. 1-7.

[5] Rosyada, A., Arina R. A., dan Indra S., 2017, "Analisis Kinerja Kondensor Unit IV Sebelum dan Sesudah Overhaul", Jurnal Politeknologi, Vol (16), No. 3, Hal. 233-8.

[6] Ali, S. H., Aklilu T. B., Suhaimi H., 2014, "Effect of Low Pressure End Conditions on Steam Power Plant Performance", MATEC Web of Conferences EDP Sciences.

[7] Data gambar dan data operasi diperoleh dari PT. Geo Dipa Energi Unit Dieng pada Januari 2018.

[8] Xie, Y., Zeng X., Ning M., 2016, "Evaluation of the Effectiveness-NTU Method for Countercurrent Humidifier", Applied Thermal Engineering, Vol (99), Hal. 1270-1276.

[9] Cengel, Y. A., 2003, "Heat Transfer: A Practical Approach", Second Edition Mc Graw-Hill, Hal. 785-841

[10] Ardhito, D. D. L., 2015, "Analisis Pengaruh Kevakuman Kondenosor Terhadap Laju Perpindahan Panas dan Efektivitas pada PLTU Rembang Unit \#10", Tugas Akhir, Universitas Gadjah Mada. 